\title{
Radiolysis of Aqueous Aniline Solutions
}

\author{
IVAN P. KARAIVANOV a and HILBERT C. CHRISTENSEN $b$
}

a Institute of Nuclear Research and Nuclear Energy, Bulgarian Academy of Sciences, Sofia, Bulgaria and b AB Atomenergi, Studsvik, Fack, S-611 01 Nyköping, Sweden

Aqueous aniline solutions have been irradiated with ${ }^{60} \mathrm{Co} \gamma$-rays. In $\mathrm{N}_{2} \mathrm{O}$-saturated solutions the following products are formed: 2-aminophenoxazine-3-one $(G=0.24)$, hydrazobenzene $(G=0.2)$, hydrogen $(G=0.36)$, and ammonia $(G=0.9)$. Furthermore, traces of azobenzene, $o$-aminophenol, diphenylamine, 2-aminobiphenyl, $N$-phenyl-o-phenylenediamine, and phenol $(G=0.01)$ are formed. After irradiation $\mathrm{N}_{2} \mathrm{O}$. saturated solutions are considerably more coloured than are the corresponding Ar- and air-saturated solutions. The yield of aniline decomposition $[G(-\mathrm{A})]$ is also higher in $\mathrm{N}_{2} \mathrm{O}$. saturated $[G(-\mathrm{A})=3.3]$ than in Ar-saturated solutions $[G(-A)=0.5]$. In the reaction mechanism presented in the report, the lower yield in Ar-saturated solutions is accounted for by back reactions between oxidized and reduced aniline radicals. A study of model compounds indicates that 2-aminophenoxazine-3-one can be formed in irradiated aniline solutions by reactions of 0 -aminophenol.

\section{INTRODUCTION}

Information about the end products formed by the radiolysis of aniline is scarce: Knight ${ }^{1}$ irradiated pure aniline with ${ }^{137} \mathrm{Cs} \beta$-rays to a dose of $4 \times 10^{21} \mathrm{eV} / \mathrm{g}$ and identified the products by means of gas chromatography. He identified 2,2-diaminobiphenyl, diphenylamine, 3,3- and 2,4-diaminobiphenyl, and hydrogen $\left[G\left(\mathrm{H}_{2}\right)=\right.$ $0.11]$ as final products. He did not find ammonia.

The only information about the end products from the radiolysis of aqueous solutions is given by Kumagai. ${ }^{2} \mathrm{He}$ identified the following products: phenol, diphenylamine, and nitrosobenzene and also traces of nitrobenzene and ammonia.

It is known that the aromatic amines are easily oxidized: If solutions of sodium metavanadate, sulfuric acid and aniline are mixed the initial products give a yellow-green colour Acta Chem. Scand. A 29 (1975) No. 5 after which an intense blue-green colour is developed. ${ }^{3}$ Oxidation of aniline with fivevalence vanadate yields products which absorb light at $410-425 \mathrm{~nm}$. The absorption has been assigned to intermediate products with the structures of the anilino radical and quinoline.

During the oxidation of aqueous aniline solutions with potassium persulfate Geverkian et al. found that azobenzene is formed when aniline is present in excess while aniline black is formed with aniline in deficit.

Udenfriend et al. ${ }^{5}$ have pointed out that the Fenton reagent oxidizes aniline to aminophenol. Aniline is transformed into $p$-aminophenol in the organism.

The aim of the present study was to obtain additional information about the end products formed by the radiolysis of aqueous aniline solutions and to study the reaction mechanism.

\section{EXPERIMENTAL}

2.1. Material. Triple distilled water was used for the preparation of solutions. Aniline was purified by distillation under vacuum in the presence of zinc dust. Ar and $\mathrm{N}_{2} \mathrm{O}$ were purified by distillation, $\mathrm{N}_{2} \mathrm{O}$ furthermore by bubbling through solutions of hydroquinone.

2.2. Preparation of samples and irradiation. The samples were prepared in ampoules by successive evacuations and saturations under shaking. After saturation the ampoules were sealed and irradiated in a Gammacell 220 (Atomic Energy of Canada Ltd) charged with ${ }^{60} \mathrm{Co}$. The dose rate was about $16000 \mathrm{rad} / \mathrm{min}$. Doses were normally in the range of $50-200$ krad. The irradiation temperature was about $30{ }^{\circ} \mathrm{C}$.

2.3. Analysis. Absorption spectra were recorded with a Beckman model B spectrophotometer. Ammonia was identified by Nessler's reagent using a Conway cell.? 
A Perkin Elmer model 800 gas chromatograph was used for the quantitative analysis of (1) hydrogen using a column with molecular sieve, (2) phenol using a trixylenyl phosphate column at $180^{\circ} \mathrm{C}$ and $o$-cresol as internal standard, (3) the decomposition of aniline using the trixylenyl phosphate column at $115^{\circ} \mathrm{C}$ and $o$. cresol and benzyl alcohol as internal standards. Qualitative and quantitative analysis of the products extracted into ether was made by gas chromatography using a $2 \mathrm{~m}$ Apiezon-L column at $180^{\circ} \mathrm{C}$.

In order to verify the products samples were also analyzed by thin layer chromatography using $\mathrm{Al}_{2} \mathrm{O}_{3}$ or $\mathrm{SiO}_{2}$ plates. The spots on the plates were analyzed by mass spectrometry.

\section{RESULTS}

3.1. Absorption spectra. The irradiated solu. tions were coloured from yellow to yellowbrown with the $\mathrm{N}_{2} \mathrm{O}$ saturated solutions yielding a higher intensity. At higher doses a precipitate was formed in $\mathrm{N}_{2} \mathrm{O}$-saturated solutions.

Most of the coloured products can be extracted with ether. Under the influence of light and air extractable coloured products are reformed in the aqueous phase undoubtedly by autoxidation of the radiolytic products. Of the products likely to be formed both hydrazobenzene and aminophenols are easily oxidized. While $m$ aminophenol is stable the $o$ - and $p$-aminophenols become rapidly dark in the presence of air and light. ${ }^{6}$ Autoxidation of concentrated aqueous solutions of $p$-aminophenol yields a precipitate of black crystals. The absorption spectrum of the precipitate dissolved in alcohol is shown in Fig. 1.

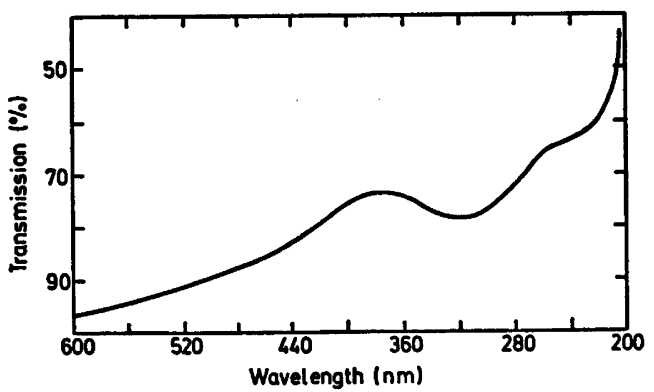

Fig. 1. Absorption spectrum of the $p$-aminophenol oxidation product dissolved in ethanol The product was obtained after exposure of an aqueous solution of $p$-aminophenol to air and day light at room temperature for $2 \mathrm{~d}$.

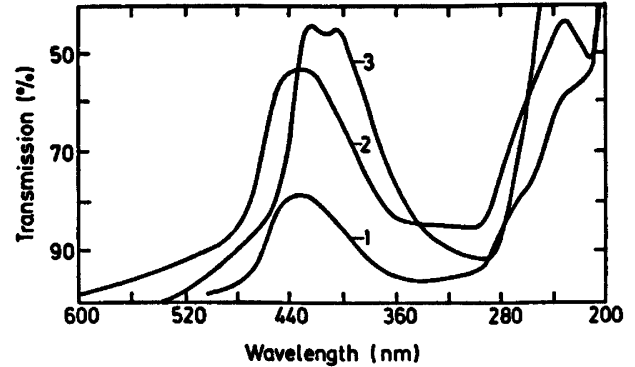

Fig. 2. Absorption spectrum of the o-aminophenol oxidation product. Solvents: $1=$ water, $2=$ ethanol and $3=$ ether. The product was obtained after exposure of an aqueous solution of $o$-aminophenol to air and day light at room temperature for $2 \mathrm{~d}$.

Autoxidation of fairly concentrated aqueous solutions of $\boldsymbol{o}$-aminophenol yields a brown precipitate which is appreciably soluble in water, methanol, ethanol and ether. The spectra of the precipitate in different solvents are compared in Fig. 2. In ethanol and methanol absorption maxima are found at 238 and $440 \mathrm{~nm}$ with an extinction coefficient of $23500 \mathrm{M}^{-1}$ $\mathrm{cm}^{-1}$ at $440 \mathrm{~nm}$. It is known that 2-aminophenoxazine-3-one is obtained as an inter-

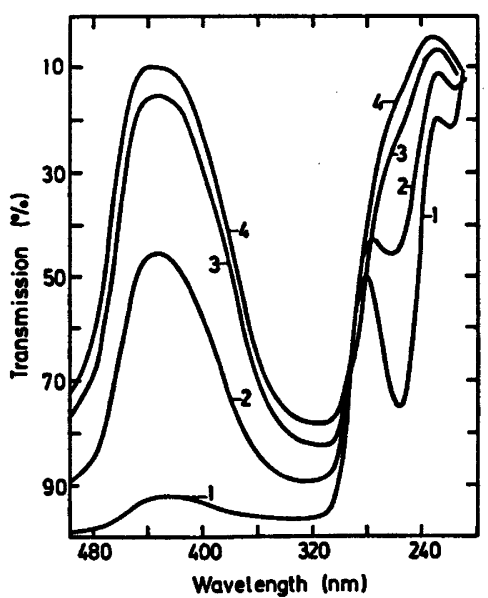

Fig. 3. Photolysis of an aerated $10^{-4} \mathrm{M}$ solution of o-aminophenol at room temperature. Absorption spectra of the oxidation product dissolved in water; (1) Within $1 \mathrm{~h}$ from dissolution of the o-aminophenol in water. (2) $1 \mathrm{~d}$ after dissolution. (3) $4 \mathrm{~d}$ after dissolution. (4) $5 \mathrm{~d}$ after dissolution. The only light source was day light. 


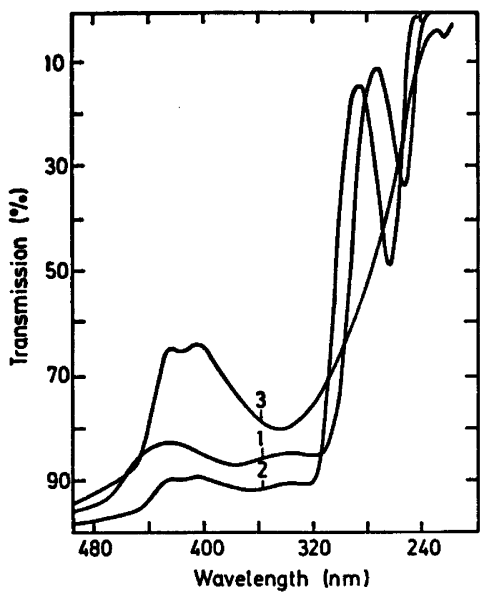

Fig. 4. Absorption spectra of (1) an irradiated aqueous aniline solution, (2) the products extracted from this solution into ether, and (3) the 0 -aminophenol oxidation product dissolved in ether.

mediate product during the oxidation of $o$ aminophenol by cytochromoxidase, ${ }^{8}$ lead dioxide, ${ }^{\circ}$ and $p$-benzoquinone..$^{10}$

The spectrum of the oxidation product obtained in this investigation is similar to that of 2-aminophenoxazine-3-one given in the literature. ${ }^{8,11,12}$ Clearly the autoxidation of $o$ -

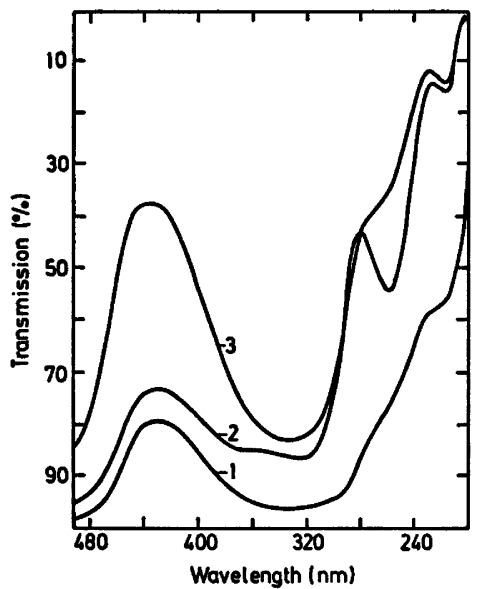

Fig. 5. Absorption spectra of aqueous solutions of (1) the o-aminophenol oxidation product, (2) the product isolated from $10^{-2} \mathrm{M}$ aniline solution irradiated at $1000 \mathrm{krad}$, and (3) solution (2) after two days of exposure to air and day light at room temperature.

Acta Chem. Scand. A 29 (1975) No. 5 aminophenol in aqueous solutions leads to the formation of 2-aminophenoxazine-3-one. At lower concentrations no precipitate is formed, the solution turns yellow, the spectrum of the solution is identical to that of 2 -aminophenoxazine-3-one and the kinetics of the oxidation can be observed. The kinetics of the oxidation of $10^{-4} \mathrm{M}$ solutions of $o$-aminophenol are indicated in Fig. 3. It can be seen that the main product is 2-aminophenoxazine-3-one; after five days about $90 \%$ of the o-aminophenol has been transformed into 2-aminophenoxazine-3-one. This compound is also formed by the irradiation of $\mathrm{N}_{2} \mathrm{O}$-saturated, $10^{-2} \mathrm{M}$ aniline solutions. In Fig. 4 the spectra of the irradiated aqueous solution and its ether extract are compared with that of 2-aminophenoxazine-3-one. It can be seen that close to $420 \mathrm{~nm}$ the spectrum of the product agrees with that of phenoxazine. The wave-length range below $320 \mathrm{~nm}$ is dominated by aniline. However, following the removal of aniline by repeated evaporations with ether, it also becomes possible to observe the spectrum of the products below $320 \mathrm{~nm}$. The spectrum of an aqueous solution of the dry residue prepared in this way is shown in Fig. 5. The maximum at $290 \mathrm{~nm}$ probably belongs to the spectrum of $o$-aminophenol since the oxidation of the extract demonstrates kinetics similar to that of $o$-aminophenol (Fig. 3). The extinction coefficient of o-aminophenol is $2.2 \times 10^{3} \mathrm{M}^{-1}$ $\mathrm{cm}^{-1} .^{13}$

3.2 Gas chromatographic analysis. The irradiated solutions were extracted with ether and the extracts analysed by gas chromatography. The following products were identified with the aid of their retention times: azobenzene, hydrazobenzene, diphenylamine, 2-aminobiphenyl, and $N$-phenyl-o-phenylenediamine.

Measurement of $G$ (Phenol) gave 0.01 in $\mathrm{N}_{2} \mathrm{O}$-saturated solutions after a dose of 1000 krad, while $G\left(\mathrm{H}_{2}\right)$ was 0.36 , a little less than the molecular yield, and $G$ (-aniline) was 0.5 and 3.3 in Ar- and $\mathrm{N}_{2} \mathrm{O}$-saturated solutions, respectively. $G$ (-aniline) was 1.2 in acid $(\mathrm{pH}=$ 2), Ar-saturated solutions.

3.3 Ammonia. The measured $G\left(\mathrm{NH}_{3}\right)$ was 0.9 in both air- and $\mathrm{N}_{2} \mathrm{O}$-saturated solutions. In Ar-saturated solutions the yield was low $(<0.1)$. 


\section{DISCUSSION}

Radiolysis of aqueous aniline solutions yields hydrogen, ammonia, 2-aminophenoxazine-3one, and hydrazobenzene. Phenol, diphenylamine, 2-aminobiphenyl, and $N$-phenyl-o-phenylenediamine are found in trace amounts.

Our results disagree to some extent with those of Kumagai ${ }^{2}$ who found phenol, diphenylamine and nitrosobenzol as the main products.

We have studied Ar-, $\mathrm{N}_{\mathbf{2}} \mathrm{O}$-, and air-saturated solutions. The following reactions may take place with rate constants expressed in $\mathrm{M}^{-1} \mathrm{~s}^{-1}$ printed after the reactions. ${ }^{14}$

$$
\begin{array}{ll}
\mathrm{H}_{2} \mathrm{O} \rightarrow \theta_{\mathrm{aq}}{ }^{-}, \mathrm{H}, \mathrm{OH}, \mathrm{H}_{2}, \mathrm{H}_{2} \mathrm{O}_{2} \\
\mathrm{e}_{\mathrm{aq}}{ }^{-}+\mathrm{N}_{2} \mathrm{O} \rightarrow \mathrm{OH}+\mathrm{OH}^{-}+\mathrm{N}_{2} & 5.6 \times 10^{\circ} \\
e_{\mathrm{aq}}{ }^{-}+\mathrm{O}_{2} \rightarrow \mathrm{O}_{2}^{-} & 1.9 \times 10^{10} \\
\mathrm{H}+\mathrm{O}_{2} \rightarrow \mathrm{HO}_{2} & 1.9 \times 10^{10}
\end{array}
$$

In neutral water the $G$-values of the primary products are: ${ }^{15} \mathrm{OH}: 2.65 ; \Theta_{\mathrm{aq}}{ }^{-}: 2.6$; $\mathrm{H}: 0.55$;

\begin{tabular}{|c|c|c|c|c|}
\hline $\begin{array}{l}\text { Satu- } \\
\text { rated } \\
\text { with }\end{array}$ & $G(\mathrm{OH})$ & $G\left(\mathrm{e}_{\mathrm{aq}}{ }^{-}\right)$ & $G(\mathbf{H})$ & $G\left(\mathrm{O}_{2}^{-}\right)$ \\
\hline $\begin{array}{l}\mathrm{Ar} \\
\mathrm{O}_{2} \\
\mathrm{~N}_{2} \mathrm{O}\end{array}$ & $\begin{array}{l}2.65 \\
2.65 \\
5.25\end{array}$ & $\begin{array}{l}2.6 \\
-\end{array}$ & $\begin{array}{l}0.55 \\
\overline{0.55}\end{array}$ & $\overline{3.15}$ \\
\hline
\end{tabular}
$\mathrm{H}_{2}: 0.45 ; \mathrm{H}_{2} \mathrm{O}_{2}: 0.7$.

The yields in water saturated with $\mathrm{Ar}, \mathrm{N}_{2} \mathrm{O}$ or $\mathrm{O}_{2}$ are

It can be seen that the sum of the oxidizing radicals $\left(\mathrm{O}_{2}^{-}, \mathrm{HO}_{2}\right.$, and $\left.\mathrm{OH}\right)$ is almost the same in the systems saturated with air and with $\mathrm{N}_{2} \mathrm{O}$.

Aniline (A) reacts with $\Theta_{\mathrm{aq}}, \mathrm{H}$, and $\mathrm{OH}$ radicals with the rate constants $2.6 \times 10^{7}$, $2.9 \times 10^{9}$, and $1.4 \times 10^{10} \mathrm{M}^{-1} \mathrm{~s}^{-1}$, respectively. ${ }^{16}$

Since $k\left(\mathbf{A}+\theta_{\mathrm{aq}}{ }^{-}\right)$is small hydrated electrons will not react with aniline in $\mathrm{N}_{2} \mathrm{O}$-saturated solutions; $e_{\mathrm{aq}}-$ is transformed instead into $\mathrm{OH}$ radicals through reaction 1 . Thus the $H$ and $\mathrm{OH}$ adducts of aniline will be initially formed according to the reactions: ${ }^{16}$

$$
\begin{aligned}
& \mathrm{C}_{6} \mathrm{H}_{5} \mathrm{NH}_{2}+\mathrm{OH} \rightarrow\left(\mathrm{C}_{6} \mathrm{H}_{6} \mathrm{NH}_{2}\right) \mathrm{OH} \\
& \mathrm{C}_{6} \mathrm{H}_{6} \mathrm{NH}_{2}+\mathrm{H} \rightarrow\left(\mathrm{C}_{6} \mathrm{H}_{6} \mathrm{NH}_{2}\right) \mathrm{H}
\end{aligned}
$$

The coloured products are formed with the highest yield in solutions saturated with $\mathrm{N}_{2} \mathrm{O}$, probably as a result of reactions between aniline and $\mathrm{OH}$ radicals. The radicals $\mathrm{H}, \Theta_{\mathrm{aq}}, \mathrm{O}_{2}^{-}$, and $\mathrm{HO}_{2}$ either form colourless products or participates in back reactions with the reformation of aniline.

In Ar-saturated solutions the low yield of coloured products is probably due to the occurrence of back reactions. This is confirmed by the low yield for the decomposition of aniline in these solutions, $G(-\mathrm{A})=\mathbf{0 . 5}$.

Due to the comparatively low value of the rate constant for the reaction between hydrated electrons and aniline, the back reaction probably follows the scheme:

$$
\begin{aligned}
& \mathrm{C}_{6} \mathrm{H}_{6} \mathrm{NH}_{2}+\mathrm{OH} \rightarrow\left(\mathrm{C}_{6} \mathrm{H}_{5} \mathrm{NH}_{8}\right) \mathrm{OH} \\
& \left.\left(\mathrm{C}_{6} \mathrm{H}_{5} \mathrm{NH}_{2}\right) \mathrm{OH}\right)+\mathrm{\theta aq}_{\mathrm{aq}}{ }^{-} \rightarrow \mathrm{C}_{6} \mathrm{H}_{5} \mathrm{NH}_{2}+\mathrm{OH}^{-}
\end{aligned}
$$

A similar reaction has been observed by Nakken ${ }^{17}$ in aqueous solutions of $p$-aminobenzoic acid (PABA) saturated with nitrogen. Since in this instance $k\left(e_{\mathrm{aq}}{ }^{-}+\mathrm{PABA}\right)$ is high $\left(2.1 \times 10^{\circ} \mathrm{M}^{-1} \mathrm{~s}^{-1}\right)$ the reaction follows the scheme:

$$
\begin{aligned}
& \mathrm{PABA}+\mathrm{O}_{\mathrm{aq}}{ }^{-} \rightarrow \mathrm{PABA}^{-} \\
& \mathrm{PABA}+\mathrm{OH} \rightarrow\left(\mathrm{PABA}^{-} \mathrm{OH}\right. \\
& (\mathrm{PABA}) \mathrm{OH}+\mathrm{PABA}^{-} \rightarrow 2 \mathrm{PABA}+\mathrm{OH}^{-}
\end{aligned}
$$

If one $\mathrm{OH}$ radical were responsible for the transformation of one molecule of aniline the decomposition yield $G(-\mathrm{A})$ in $\mathrm{N}_{2} \mathrm{O}$-saturated solutions would be about 5 . The measured $G(-\mathrm{A})$ of 3.3 obtained here indicates either the occurrence of reactions which lead back to aniline or the participation of $\mathrm{OH}$ radicals in secondary reactions. $o$-Aminophenol and 2 aminophenoxazine-3-one could be formed in such reactions:

$$
\begin{aligned}
& \left(\mathrm{C}_{6} \mathrm{H}_{6} \mathrm{NH}_{2}\right) \mathrm{OH}+\left(\mathrm{C}_{6} \mathrm{H}_{5} \mathrm{NH}_{2}\right) \mathrm{OH} \rightarrow \\
& \mathrm{NH}_{2} \mathrm{C}_{6} \mathrm{H}_{4} \mathrm{OH}+\mathrm{C}_{6} \mathrm{H}_{5} \mathrm{NH}_{2}+\mathrm{H}_{2} \mathrm{O} \\
& \mathrm{NH}_{2} \mathrm{C}_{6} \mathrm{H}_{4} \mathrm{OH}+\mathrm{OH} \rightarrow \\
& \text { 2-aminophenoxazine-3-one }
\end{aligned}
$$

We have verified that 2-aminophenoxazine3 -one is formed by reaction between 0 -aminophenol and $\mathrm{OH}$ radicals, during the irradiation of aqueous, $\mathrm{N}_{2} \mathrm{O}$-saturated solutions of $o$. aminophenol. The irradiation of aniline solutions yielded $o$-aminophenol only at high doses (500 krad) whereas at doses of $200 \mathrm{krad}$ or less only 2-aminophenoxazine-3-one was found. 
This indicates that the latter product may be formed without the participation of o-amino. phenol as an intermediate product.

Hydrazobenzene is formed by recombination of anilino radicals:

$$
\mathrm{C}_{6} \mathrm{H}_{5} \mathrm{NH}+\mathrm{C}_{6} \mathrm{H}_{5} \mathrm{NH} \rightarrow \mathrm{C}_{6} \mathrm{H}_{5} \mathrm{NHNHC}_{6} \mathrm{H}_{5}
$$

The formation of anilino radicals in these systems has been demonstrated by means of flash photolysis ${ }^{18}$ and pulse radiolysis. ${ }^{16}$

Ammonia and phenol might be formed according to the reactions 4,5 , and 13 .

$$
\begin{aligned}
& \left(\mathrm{C}_{8} \mathrm{H}_{5} \mathrm{NH}_{2}\right) \mathrm{OH}+\left(\mathrm{C}_{6} \mathrm{H}_{5} \mathrm{NH}_{2}\right) \mathrm{H} \rightarrow \\
& \mathrm{C}_{6} \mathrm{H}_{5} \mathrm{OH}+\mathrm{C}_{6} \mathrm{H}_{5} \mathrm{NH}_{2}+\mathrm{NH}_{3}
\end{aligned}
$$

The measured $G\left(\mathrm{H}_{2}\right)$ of 0.36 obtained in Arsaturated solutions is a little lower than the molecular yield. This shows that hydrogen is not formed by the abstraction of $\mathrm{H}$ atoms from aniline.

\section{CONCLUSION}

Irradiation of aqueous aniline solutions yields coloured products, mainly as a result of attack by $\mathrm{OH}$ radicals. The participation of the radicals $\mathrm{H}, \Theta_{\mathrm{aq}}{ }^{-}$and $\mathrm{O}_{2}^{-}$in the reactions leads to a decrease in the yield of coloured products. In Ar-saturated solutions the decrease is probably due to the participation of hydrated electrons in back reactions. Of the products identified the following are the most important: 2aminophenoxazine-3-one (0.24), $o$-aminophenol, hydrazobenzene (0.2), ammonia $(0.9)$ and phenol (0.01), the yields in $\mathrm{N}_{2} \mathrm{O}$-saturated solutions being given in parenthesis. The yields of hydrogen and phenol and the aniline decomposition yield have also been determined. Molecular hydrogen is not formed by the abstraction of $\mathrm{H}$ atoms from aniline.

\section{REFERENCES}

1. Knight, J. A., Jr., AEC rep. ORO-3519-3 (1969).

2. Kumagai, H. Nippon Igaku Hoshasen Gakkai Zasshi 21 (1962) 971.

3. Yatsimirskii, K. B. and Nikolov, G. S. Zh. Fiz. Khim. 44 (1970) 1400.

4. Gevorkyan, M. G., Beileryan, N. M. and Chaltykyan, O. A. Arm. Khim. Zh. 22 (1969) 288.

5. Udenfriend, S., Clark, C. T., Axelrod, J. and Brodie, B. B. J. Biol. Chem. 208 (1954) 731.

Acta Chem. Scand. A 29 (1975) No. 5
6. Kirk, R. E. and Othmer, D. F., Ed., Encyclopedia of Chemical Technology, Interscience Encyclopedia, New York 1948, Vol. 2, p. 229.

7. Borsok, H. and Dubnoff, J. W. J. Biol. Chem. 131 (1939) 163.

8. Nagasawa, H. T., Gutmann, H. R. and Morgan, M. A. J. Biol. Chem. 234 (1959) 1593.

9. Fischer, R. and Jonas, O. Ber. Deut. Chem. Ges. 27 (1894) 2782.

10. Abdel-Megud, O. and Ismail, B. J. Amer. Chem. Soc. 82 (1960) 1607.

11. Gerber, N. N. and Lechevalier, M. P. Biochemistry 3 (1964) 598.

12. UV Atlas of Organic Compounds, Butterworth, London 1966, No. 71.

13. Bol'shakov, G. F., Vatago, V.S. and Agrest, F. B. Ultrafioletovie spektri heteroorganicheskij soedinenii, Izd. Khimiya, Leningradskoe otdelenie 1969.

14. Anbar, M. and Neta, P. Int. J. Appl. Radiat. Isotopes 18 (1967) 493.

15. Dorfman, L. M. and Matheson, M. S. Progr. React. Kinet. 3 (1965) 237.

16. Christensen, H. C. Int. J. Radiat. Phys. Chem. 4 (1972) 311.

17. Nakken, K. F. Radiat. Res. 21 (1964) 446.

18. Land, E. J. and Porter, G. Trans. Faraday Soc. 59 (1963) 2027.

Received December 19, 1975. 